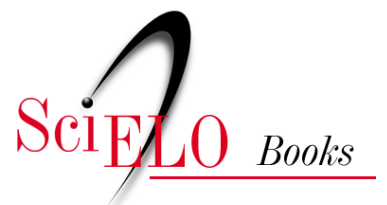

\title{
11 - O uso da internet pela rede xique-xique enquanto articulação entre campo/cidade
}

\author{
Jhose Iale C. da Cunha Vieira \\ Moacir Vieira da Silva
}

\section{SciELO Books / SciELO Livros / SciELO Libros}

VIEIRA, J. I. C. C., and SILVA, M. V. O uso da internet pela rede xique-xique enquanto articulação entre campo/cidade. In: OLIVEIRA, G. M. C., and VIEIRA, K. M. A., eds. Patrimônio, povos do campo e memórias: diálogos com a cultura, a arte e a educação [online]. Mossoró: EdUFERSA, 2020, pp. 165-178. ISBN: 978-65-87108-09-4. https://doi.org/10.7476/9786587108605.0012.

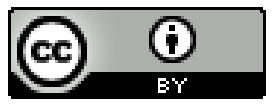

All the contents of this work, except where otherwise noted, is licensed under a Creative Commons Attribution 4.0 International license.

Todo o conteúdo deste trabalho, exceto quando houver ressalva, é publicado sob a licença Creative Commons Atribição 4.0. 


\section{O USO DA INTERNET PELA \\ REDE XIQUE-XIQUE ENQUANTO \\ ARTICULAÇÃO ENTRE CAMPOI \\ CIDADE ${ }^{43}$}

Jhose Iale C. da Cunha Vieira

Moacir Vieira da Silva

\section{Introdução}

Dentre as várias transformações que vêm ocorrendo nas sociedades, a difusão em massa das tecnologias informacionais certamente pode ser situada como uma das mais impactantes, com desdobramentos ainda pouco explorados em estudos sociológicos no Brasil. A internet e as redes sociais, assim como a robótica e a inteligência artificial, estão redefinindo os processos de interação social e modificando profundamente as condições espaço-tempo em que se dão as relações sociais.

Em um cenário contemporâneo e globalizado, as pessoas recorrem cada vez mais aos meios de informação para guiar seu processo de tomada de decisão e ordenar sua interação social. Segundo Castells (2003, p. 13), a criação da internet representa "a história de uma aventura humana extraordinária", porque ela possibilita transformações inimagináveis, nas mais diferentes esferas: social, econômica, política e educacional.

Uma das principais características da internet é permitir a comunicação a distância e em rede, através da digitalização de conteúdos e mensagens (MISKOLCI; BALIEIRO, 2018). A disseminação dos dispositivos móveis na

43 presente artigo traz uma versão revisada e ampliada do trabalho apresentado no $19^{\circ}$ Congresso Brasileiro de Sociologia-SBS-GT 36, Sociologia Digital. 
sociedade pós-industrial permitiu também uma desterritorialização das diferentes relações sociais e econômicas, em que se evidencia uma cultura fundamentada na virtualidade, onde a dicotomia tempo e espaço são issealdadeas, fazendo com que, de acordo com Thompson (2008), se altere as concepções de distância e se reestruture novos padrões de interações sociais; e ocorra, nas palavras de Castells (2007), uma quebra das barreiras temporais antes existentes, que dificultavam a comunicação.

Com o surgimento, disseminação e efervescência das mídias digitais, cria-se uma gama de possibilidades de comunicação, sendo possível ter contato com diversas pessoas em espaços diferentes e em tempo real (e de forma instantânea) por meio das mais variadas plataformas de comunicação, dentre elas, as redes sociais, que estão em rápida expansão.

O Digital 2020 Global Overview Report, divulgado em janeiro do referido ano, pelos serviços online Hootsuite e We Are Social, apontam que mais de 4,5 bilhões de pessoas no mundo já contam com acesso à internet, expressando um crescimento de 7\% (298 milhões de novos usuários) em relação ao ano anterior. A pesquisa relata ainda que o número de usuários de mídias sociais chega a 3,8 bilhões em todo o mundo, existindo um aumento de $9 \%$ comparado ao ano 2019 (o que representa 321 milhões de novos usuários).

O Brasil, de acordo com os dados do Global Digital Report $2020^{44}$, é o terceiro país que mais fica online: são, em média, $9 \mathrm{~h} 17 \mathrm{~m}$ todos os dias, ficando atrás apenas das Filipinas, que lidera o ranking, com uma média 9h45m, e África do Sul, com uma média de 9h22. Os Dados do Comitê Gestor de Internet, referentes ao ano de 2018, apontam que $67 \%$ dos domicílios brasileiros (46,5 milhões de domicílios) estão conectados à internet. Quando se observa a evolução dos números de usuários de internet no território nacional ao longo dos últimos 10 anos, observa-se um aumento progressivo, sendo que no último ocorreu o maior crescimento em relação

44 Dados retirado do site We Are Social: https://wearesocial.com/blog/2020/01. Acesso em: 19 mar. 2020. Esses dados levam em conta o acesso feito a partir de qualquer dispositivo e foi obtido por meio de pesquisa com usuários de 16 a 64 anos de idade. 
a 2008, passando de 61\%, em 2017 para 67 \% em 2018 (CGI, 2019). Frisa-se que este aumento está relacionado, principalmente, ao uso dos dispositivos móveis.

O Censo Agropecuário 2017, publicado em 2018, também aponta que o acesso à internet teve um salto exponencial no meio rural - numericamente falando, um avanço de 1.900\%; a exemplo disso, o número de estabelecimentos agropecuários conectados em 2006 era de apenas 75 mil, passando para 1.430.156 em 2017 (IBGE, 2018).

Posto isso, o presente texto é resultado de uma sistematização de parte dos dados coletados na fase exploratória de uma pesquisa maior que se propõe investigar as práticas cotidianas de uso da internet no contexto rural utilizando a abordagem teórico metodológica do mapa das mediações de Martín-Barbero (2015). De forma específica e para esse capítulo, tem-se como objetivo discutir a articulação campo e cidade a partir do uso da internet pelos integrantes da Rede Xique-Xique de Comercialização Solidária (RXX).

Destaca-se que as entrevistas e observações empíricas foram conduzidos mediante o acompanhamento das atividades dos integrantes da rede (sujeitos da investigação); o recorte espacial deste estudo compreende o contexto rural de uma das regiões mais vulneráveis, do ponto de vista econômico e social, do Brasil - o semiárido do Nordeste, em especial o estado do Rio Grande do Norte.

Desta forma, além dessa introdução, que situa um pouco o contexto no qual a pesquisa se inscreve, serão apresentadas ainda duas partes: uma parte referente a articulação campo/cidade e o mapa das mediações proposto por Martín-Barbero; a outra, sobre a Rede Xique Xique de Comercialização Solidária e sua relação com a internet; e por fim algumas considerações finais sobre a pesquisa.

\section{O mapa das mediações de Martín-Barbero}

Jesús Martín-Barbero (2015) foi um dos mais relevantes autores dos estudos das mediações. Para ele, "o campo daquilo que denominamos mediações é constituído pelos diversos dispositivos através dos quais a hegemonia 
transforma por dentro o sentido do trabalho e da vida da comunidade" (MARTÍN-BARBERO, 2015, p. 265).

Em seu livro Dos Meios às Mediações, Jesús Martín-Barbero (2015) abre o debate sobre o papel da comunicação na formação de novos modelos de sociedade e na inserção da cultura como um fator de mercado. Assim, o autor aponta que "a comunicação e a cultura constituem hoje um campo primordial de batalha política” (2015, p. 13).

Essa perspectiva contempla todo o processo de comunicação e não apenas a teoria da recepção. Para Martín-Barbero a comunicação não é apenas os meios; nesse sentido, ele muda o foco dos estudos dos meios de comunicação para as mediações, pois acreditava ser impossível compreender a importância que estes tinham na vida das pessoas sem estudar a vida delas, se opondo, portanto, a versão hegemônica norte americana de estudos de efeitos dos meios (MARTÍN-BARBERO; BARCELOS, 2000).

Para Martín-Barbero, mediações se refere a tudo que configura a cultura cotidiana. Para ele e Sonia Munhoz (1992 apud LOPES, 2018, p. 15):

As mediações são esse 'lugar' de onde é possível compreender a interação entre o espaço da produção e o da recepção: o que [a mídia] produz não responde unicamente a requerimentos do sistema industrial e a estratagemas comerciais, mas também a exigências que vêm da trama cultural e dos modos de ver.

Esse conceito de mediações é visto como operatório, onde o autor vai apresentar algumas dimensões que facilitam a compreensão desse instrumento metodológico. Após os dois primeiros mapas das mediações, MartínBarbero (2018) apresenta novas armações, compostas com os seguintes elementos de análise: a tecnicidade, a institucionalidade, a socialidade, a ritualidade, a temporalidade, a espacialidade e a mobilidade.

Escosteguy (2019) elabora um novo mapa a partir da junção dos elementos desenvolvido por Barbero, para melhor analisar o uso das tecnologias informacionais no contexto rural do sul do Brasil. Tal mapa será utilizado, em parte (tecnicidade, socialidade, ritualidade e mobilidade), para analisarmos os dados coletados em campo, a serem utilizados no presente texto. 
Figura 1 - Mapa de Chave teórico-analítica para um estudo socioantropológico de TICS

COMUNICAÇÃO / CULTURA

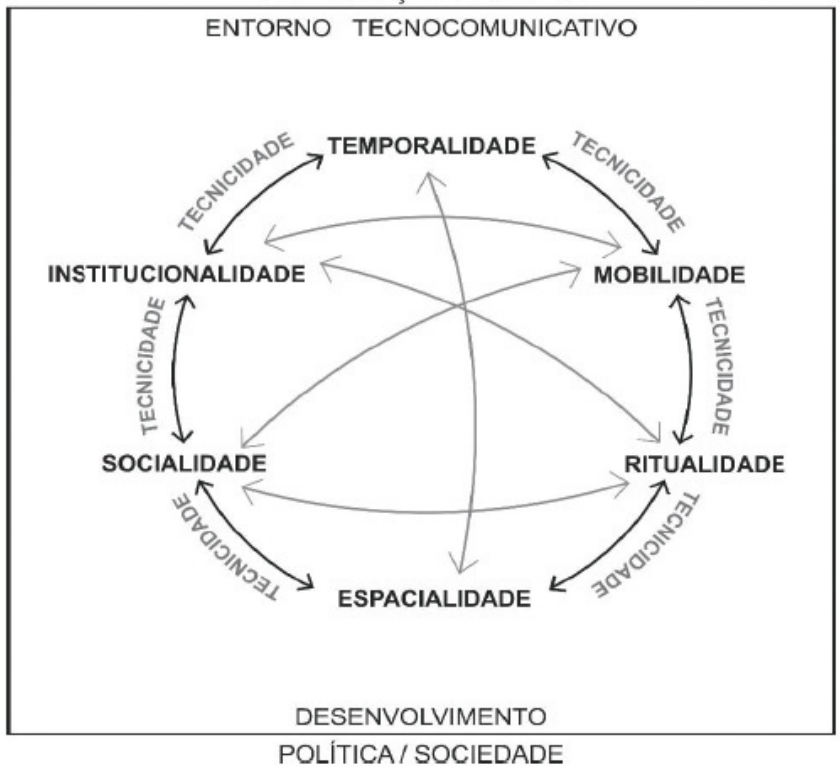

Fonte: Escosteguy (2019).

Sobre as mediações é importante destacar que a tecnicidade perpassa todas as demais, ocupando um lugar central, uma vez que ela é entendida como o modo pelo qual os indivíduos se relacionam com os suportes e formatos, isto é, com aparatos tecnológicos; vale destacar ainda que a socialidade na teoria barberiana, é medida pelo laço social e as relações cotidianas das pessoas enquanto agentes, ou seja, é constituída por um sistema de referências socioculturais que afetam o tipo de incorporação que se faz das TICs.

De acordo com o trabalho de Escosteguy, Felippi e Sifuentes (2020, p. 217):

a ritualidade refere-se às práticas acionadas nos usos regulares e repetidos que se faz das tecnologias de comunicação, tornando-se rotinas e, muitas vezes, interferindo na organização de outras atividades domésticas, assim como laborais; [...] a mobilidade está relacionada 
ao trânsito constante, tanto físico quanto virtual, entre diferentes espaços e tempos, com frequência significando uma "viagem", real ou imaginária, sobretudo, ao universo urbano.

Conforme já foi mencionado acima, no presente trabalho as dimensões de tecnicidade, socialidade, ritualidade, espacialidade e mobilidade serão as que terão maior ênfase dentre as dimensões do mapa das mediações comunicativas da cultura. Elas ajudarão na compreensão das práticas cotidianas de uso da internet no espaço rural, que surge na medida em que dispositivos tecnológicos criam situações que configuram novas formas de interação social. Estes processos modificam a performance e as práticas de indivíduos ou grupos familiares quando passam a se conectar a uma rede social e sentir-se integrados e reconhecidos neste espaço, ampliando as oportunidades de trabalho e comércio e trocas de bens e serviços.

\title{
A Rede Xique-Xique de comercialização solidária e sua relação com a internet enquanto articulação campo/cidade
}

\begin{abstract}
A Rede Xique-Xique ${ }^{45}$ (RXX) é uma organização que surgiu em 2003, de um contexto sócio histórico e geograficamente determinado, em que se debate as estratégias de convivência com o semiárido; composta por produtores rurais do Oeste Potiguar, essa rede procura uma forma mais justa de comercializar os produtos. Segundo França et al. (2011, p. 2), a RXX “possui um alto potencial de expansão da diversificação da agricultura familiar, indispensável na criação de mercados e de oportunidades no meio rural, e no fortalecimento dos mercados local e regional".

A Rede Xique-Xique tem como princípios norteadores a agroecologia, a economia solidária e o feminismo; o grupo base do empreendimento é formado por agricultores familiares (presença majoritária de grupos rurais, 80\%), com uma participação mais ativa das mulheres na comercialização
\end{abstract}

45 O bioma da caatinga, presente no Nordeste, é frequentemente simbolizado pelo Xique-Xique, planta que resiste a seca e próspera mesmo em contextos de clima e solo mais adversos. Foi a resistência dessa planta que deu nome à Rede XiqueXique, pois de acordo com a coordenadora, a rede representa resistência, a falta de dinheiro, a falta de produtos, a tudo que pode vir pela frente. 
(90\%); porém há também a representação de grupos urbanos dedicados ao artesanato e grupos de pescadores. É importante destacar aqui que os grupos variam muito em seus tamanhos, "podendo ser grupos formais ou informais, unidades familiares, associações ou cooperativas. Há desde grupos informais constituídos de seis famílias até cooperativas com 200 associados" (RIBEIRO; GALIZONI; ASSIS, 2012, p. 98).

Em entrevista com um dos responsáveis pelo ponto fixo da Rede XiqueXique, o mesmo comentou que quase todo o processo de comunicação da RXX passa pela internet. No que tange ao uso da internet ligado aos aspectos econômicos, é importante destacar que semanalmente, é disponibilizado, por meio do grupo do WhatsApp, intitulado Consumo Solidário, uma tabela de preços com o valor de cada produto ${ }^{46}$.

Os pedidos são realizados durante a segunda e a terça-feira, no horário das 7 às 17h; em tal processo, é possível observar uma interação por parte dos articuladores da rede, que anotam todas as solicitações, com os consumidores, que realizam os seus pedidos, estes que vão compor a cesta que ficará pronta na sexta-feira, dia de sua retirada no ponto fixo. Além do grupo de Consumo Solidário, é possível realizar a compra de produtos por meio da internet, através do site Cirandas.com, onde o consumidor pode escolher os produtos, como se fosse em um mercado, colocando todos os itens na cesta, que é entregue na sexta-feira.

É importante destacar que tais plataformas digitais permitem uma aproximação entre o campo/cidade, na medida em que há um diálogo entre os representantes da rede com os produtores (que residem no campo) para que seja repassado a demanda dos consumidores (que em grande maioria residem na cidade) a fim de que seja possível a entrega do produto no sexta-feira durante a feira da Rede Xique Xique. Pode-se dizer que a RXX trabalha com um pré-agendamento de pedidos, e se utiliza da internet como ponte de comunicação para tal.

46 Alguns dos produtos comercializados pela RXX são os diversos legumes, frutas, verduras, mel e seus derivados, ovo caipira, bolos, queijos, assim como também artesanatos variados. 
Tal ação pode ser realizada em qualquer espaço, seja na comodidade do lar, seja no espaço de trabalho, não havendo a necessidade do contato face-a-face para haver a interação. Aqui é possível fazer referência ao mapa das mediações, no que diz respeito a uma dimensão da mobilidade, uma vez que tal prática permite uma conexão e aproximação entre esses contextos e o trânsito entre os espaço físico e virtual, como também a dimensão de ritualidade, que "relaciona-se com as rotinas de trabalho na produção cotidiana em operação cultural, com a ação da repetição baseada nas regras que tornam possível a expressão do sentido" (RONSINI, 2011, p. 84), todas perpassadas pela tecnicidade, uma vez que estão fazendo uso das tecnologias para o desenvolvimento das suas atividades laborais.

Depois desses processos interativos, no qual a internet se apresenta como tendo um papel primordial, é realizado por parte do núcleo administrativo da rede, uma sistematização de todos os pedidos, sendo colocado em uma planilha do Excel para uma melhor distribuição, ficando mais evidente o quantitativo de produtos necessários para atender a demanda dos consumidores. Vale ressaltar que a comunicação com alguns dos agricultores precisa ser realizada por meio de áudios via aplicativo do WhatsApp, e/ou telefone, uma vez que alguns produtores possuem um baixo índice de escolaridade (analfabetos), dificultando um pouco o processo. Entretanto, acredita-se que o aplicativo possui essa via "inclusiva" na medida em que permite que haja essa comunicação de fácil compreensão.

A representante da Rede Xique-Xique informou que utiliza a internet $\mathrm{e}$ a plataforma do WhatsApp para se comunicar com os produtores; alguns perguntam o que foi escrito quando a mesma esquece de fazer áudio, mas ela reitera que sempre procura falar por meio dos áudios para que a informação chegue a todos. É importante destacar ainda que há uma grande utilização dos perfis da RXX nas redes sociais como Facebook e Instagram, além do site ${ }^{47}$ institucional mantido pela organização. Isso vem auxiliando tanto no processo de comercialização como na divulgação dos produtos e nas ações

47 https://redexiquexique.wixsite.com/redexiquexique. 
desenvolvidas pela RXX, fazendo com que seja construída uma memória desse grupo, de forma processual e colaborativa, podendo ser configurado como um patrimônio em rede.

Ainda com relação às mediações da teoria de barberiana, é possível notar aspectos ligados a socialidade, uma vez que ao verificar a percepção que os produtores vinculados a RXX têm sobre a internet, evidencia-se aspectos ligados à manutenção e criação de laços e relações sociais, uma vez que é possível por meio da internet ter contato com familiares e amigos que se encontram distantes fisicamente.

Um produtor vinculado a RXX destacou:

Eu tenho um filho que está na Irlanda, fazendo um curso de inglês, ai é bom, sabe? Ele liga para mim, eu vejo ele, online, né? Em tempo real.. ele tá lá visitando umas coisas, aí ele me mostra, me liga aí pronto.. é muito importante pra isso aí, porque antes um filho desse ia embora para São Paulo, né? E você nunca mais via...então pra muitas coisas, quando você usa bem internet, é muito bom.

Observar-se com essa fala que a internet tem permitido a manutenção de laços familiares.

Ainda com relação a mediação de socialidade, é possível observar a incidência das relações de gêneros e geracional no tocante ao uso das TICs. De acordo com uma produtora, em sua comunidade existe uma senhora idosa que procura saber das fofocas dos vizinhos por meio da internet. A mesma não sabe utilizar a ferramenta, porém gosta sempre de perguntar a filha, esta que faz essa mediação relatando-lhe o que está acontecendo. A referida senhora atribui o termo "fofoqueiro" ao aplicativo WhatsApp.

Observa-se um uso diferenciado do aparelho com relação a diferentes integrantes da família dos produtores entrevistados. Em linhas gerais, os mais jovens fazem um maior uso do celular, que se apresenta como um artefato importante na manutenção das relações familiares; uma agricultora entrevistada destacou que o celular dela era muitas vezes utilizado pela neta - que não chorava enquanto assistia vídeos no YouTube, sendo possível enquadrar as mediações tanto de ritualidade como de tecnicidade, já expostas. 
O dispositivo foi mencionado por algumas informantes por sua utilidade no cuidado com os filhos e netos, servindo como uma "babá eletrônica". Ou seja, aqui é interessante destacar as alterações nas práticas sociais e culturais com a inserção do aparato tecnológico e a sua representação.

Aqui cabe mencionar um outro espaço de mediação utilizado por MartinsBarbero - a competência cultural — onde fica visível a influência do pensamento de Bourdieu na teoria do autor, que vai definir como competência cultural as formas de pensar, agir e sentir a experiência social, sendo a etnia, a cultura regional e a classe social alguns de seus principais conformadores.

\section{Considerações Finais}

Desta forma é possível observar que a internet no meio rural tem perpassado as diversas esferas da vida cotidiano, permitindo que aconteça uma melhoria no contexto local uma vez que demonstra aspectos ligados às estratégias de reprodução social e de desenvolvimento do meio rural. Ela se apresenta com um mecanismo de articulação entre campo/cidade, uma vez que permite que tais espaços se configurem enquanto um contínuo.

Percebeu-se que a internet é vista por parte de alguns informantes como um meio através do qual é possível acessar informações que poderão facilitar o processo de desenvolvimento bem como ter conhecimento de políticas públicas; ela tem se configurado com um dispositivo de lazer e reconfiguração de espaços sociais.

Em alguns relatos foi possível perceber que a internet permitiu determinadas reconfigurações nas práticas sociais, por exemplo, com relação ao hábito, comum no meio rural nordestino, de conversas ao redor do alpendre ao final da tarde. As mesmas continuaram a acontecer com a chegada dos telefones celulares, porém, agora eles fazem parte do cenário. Todos ficam conectados, e os assuntos muitas vezes giram em todo do que é visto nas redes sociais. Nesse sentido é possível inferir que há um certo contínuo entre os espaços online e off-line, sendo pertinente investigar se tais interações têm contribuído para a permanência dos jovens no meio rural.

Portanto, pode-se dizer que o meio rural vem passando por inúmeras transformações sobretudo nos últimos anos com a proliferação dos smartphones e a disseminação da internet. Em uma região em que há uma 
dinâmica econômica menos intensa, a possibilidade de utilização de um dispositivo conectado à rede, permite a redefinição de inúmeras práticas, que variam com relação às questões de gênero e geração.

As práticas cotidianas em relação ao uso das TIC vão desde a aspectos ligados a comunicação (entre amigos, familiares e vizinhos) até contexto relacionados a ampliação de oportunidades e acesso a novos mercados, sendo uma ferramenta que permite ampliar a renda, encurtar distâncias e estabelecer elos "invisíveis" entre espaços diversos, a exemplo do campo e da cidade. Assim, o acesso à internet no meio rural de uma região de elevados índices de vulnerabilidade tem permitido ao agricultor uma maior autonomia, acesso a novas oportunidades, reforçando as práticas comunicativas e ressignificando a própria identidade e o contexto ao qual faz parte. 


\section{REFERÊNCIAS}

CASTELLS, M. A sociedade em rede: a era da informação: economia, sociedade e política. 10. ed. São Paulo: Paz e Terra, 2007.

CASTELLS, M. A Galáxia da internet: reflexões sobre a internet, os negócios e a sociedade. Rio de Janeiro: Zahar, 2003.

COMITE GESTOR DE INTERNET. Pesquisa sobre o uso das tecnologias de informação e comunicação no Brasil. 2018.

Disponível em: http://www.cetic.br. Acesso em: 02 out. 2018.

ESCOSTEGUY, A. C. As Tecnologias de informação e comunicação em perspectiva teórico-analítica. In: ESCOSTEGUY, A. C. et al. As Tecnologias da comunicação no cotidiano de famílias rurais: (re) configurações de uma ruralidade. Santa Cruz do Sul: EDUNISC, 2019. p. 15-31. Disponível em: https://bit.ly/2RsyWum. Acesso em: 12 set. 2019 ESCOSTEGUY, A. C. D.; FELIPPI, Â. C. T.; SIFUENTES, L.

Reconfigurações do espaço rural e do cotidiano familiar: os sujeitos e suas práticas com as tecnologias de comunicação. Redes, v. 25, n. 1, jan. 2020.

FRANÇA, A. R. M. et al. A Dinâmica da agricultura familiar e a economia solidária: a experiência de inserção em mercados e a diversificação da Rede Xique Xique (RN). In: CIRCUITO DE DEBATES ACADÊMICOS, 1. , 2011, Brasília. Anais [...]. [S.l.]: IPEA, 2011. p. 6. 
IBGE-INSTITUTO BRASILEIRO DE GEOGRAFIA E ESTATÍSTICA. Censo agropecuário 2017: agricultura familiar: Brasil, Grandes Regiões e Unidades da Federação: primeiros resultados. Rio de Janeiro: IBGE, 2018.

LOPES, M. I. V. Jesús Martín-Barbero e os mapas essenciais para compreender a comunicação. Intexto, [S.l.], n. 43, p. 14-23, 2018. MARTÍN-BARBERO, J.; BARCELOS, C. Comunicação e mediação. Diálogos midiológicos, v. 23, n. 1, p. 153-163, 2000.

MARTÍN-BARBERO, J. Dos meios às mediações: comunicação, cultura e hegemonia. 7. ed. Rio de Janeiro: UFRJ, 2015.

MARTÍN-BARBERO, J. Dos meios às mediações: três introduções.

Matrizes, v. 12, n. 1, p. 9-31, 2018. Disponível em: http://www.revistas. usp.br/matrizes. Acesso: 06 jun. 2019.

MISKOLCI, R.; BALIEIRO, F. F. Sociologia Digital: balanço provisório e desafios. Revista Brasileira de Sociologia, v. 6, p. 132-154, 2018.

RONSINI, V. V. M. A Perspectiva das mediações de Jesús Martín Barbero. In: GOMES JÚNIOR, I. M. M.; JANOTTI, J. (org.). Comunicação e Estudos culturais. Salvador: UFBA, 2011.

RIBEIRO, E. M.『 GALIZONI, F. M.『ASSIS, T. P. (Org.). Comercialização solidária no Brasil: uma estratégia em rede. Porto Alegre: EDIPUCRS, 2012.

THOMPSON, J. B. A Mídia e a modernidade: uma teoria social da mídia. 10. ed. Petrópolis: Vozes, 2008. 